\title{
O que Sabes Tu que Cuidas de Mim? - Características e Necessidades em Saúde da Mulher Cabo-Verdiana
}

\begin{abstract}
Carolina Henriques ${ }^{1}$, Paulo Santos ${ }^{2}$ e João Frade ${ }^{3}$
${ }^{1}$ Doutorada em Enfermagem, Professora Coordenadora, Departamento de Ciências de Enfermagem, Center for Innovative Care and Health Technology (ciTechCare), Politécnico de Leiria, Portugal | carolina.henriques@ipleiria.pt | https://orcid.org/0000-0002-0904-8057

${ }^{2}$ Doutorado em Enfermagem, Professor Adjunto, Center for Interdisciplinary Research in Health (CIIS), Universidade Católica Portuguesa, Lisboa, Portugal | paulofigueiredosantos@gmail.com | http://orcid.org/0000-0001-7409-1011

${ }^{3}$ Doutorado em Saúde Pública, Professor Adjunto, Departamento de Ciências de Enfermagem, Center for Innovative Care and Health Technology (ciTechCare), Politécnico de Leiria, Portugal | joao.frade@ipleiria.pt | https://orcid.org/0000-0002-4947-1052

Resumo: O trabalho recai sobre elas, mulheres cabo-verdianas, a apanha da lenha para a fogueira, procurando pão para os filhos, de cesta na mão, regressando do campo. Dos trabalhos informais aos formais, as mulheres cabo-verdianas sobreviveram entre o colonizador português e o homem cabo-verdiano. Conhecermos de que forma os enfermeiros cabo-verdianos perspetivam a mulher cabo-verdiana, foi o mote para este trabalho, onde se procura, não só aceder à perspetiva dos enfermeiros sobre as características da mulher cabo verdiana, tal como, às necessidades em saúde destas mulheres. Recorreu-se à metodologia qualitativa da análise de conteúdo de Bardin. Concluímos que as mulheres cabo-verdianas, ainda hoje, são caracterizadas como mulheres trabalhadoras, centradas ao espaço doméstico, muitas vezes vítimas de violência de género, e com baixa literacia. Face às necessidades em saúde, identifica-se que os enfermeiros consideram como necessário o acesso destas mulheres a consultas gratuitas e a melhores cuidados no domínio da saúde materna e obstétrica.
\end{abstract}

Palavras-chave: Mulher; Cabo Verde; Análise de Conteúdo; Qualitativo.

What Do You Know Who Cares About Me? - Cape-Verdean Women's Health Characteristics and Needs

\begin{abstract}
The work falls on them, gathering firewood for the fire, looking for "bread-for the children", basket in hand, returning from the field. From informal to formal jobs, Cape Verdean women survived between the Portuguese colonizer and the Cape Verdean man. Knowing how Cape Verdean nurses perceive Cape Verdean Women was the motto for this work, which seeks to not only access nurses' perspective on the characteristics of Cape Verdean women, as well as the health needs of these women. Bardin's qualitative content analysis methodology was used. We conclude that Cape Verdean women, even today, are characterized as working women, focused on the domestic space, often victims of gender violence, and with low literacy. In view of the health needs, it is identified that nurses consider it necessary for these women to have free consultations and better care in the field of maternal and obstetric health.
\end{abstract}

Keywords: Woman; Cape Verdean; Content Analysis; Qualitative.

\section{Introdução}

A mulher cabo-verdiana desde sempre vivenciou uma situação de pobreza económica e social. Relegada para segundo plano, a mulher cabo-verdiana, numa cultura de hegemonia masculina, teve durante muitos anos pouca participação ao nível do poder político e social. Trabalhadora dentro da esfera privada e cuidadora dos filhos e da família, a mulher cabo-verdiana foi-se vendo relegada para segundo plano. O espaço doméstico, considerado inato à mulher, foi onde estas mulheres exerceram o seu papel de mães, esposas, cuidadoras de dependentes e empregadas domésticas. Segundo Gomes (2011) as mulheres cabo-verdianas foram excluídas da vida pública e incluídas na vida privada. Foram consideradas em muitas situações, meramente "objeto de reprodução" e a questão da educação era vista como um direito exclusivamente dos homens, ou seja, "segundo a cultura patriarcal, as raparigas não necessitavam de aprender a ler e a escrever para serem boas esposas e boas donas de casa" (Gomes, 2011, p.106). 
Quase como se de um destino traçado se tratasse, as mulheres cabo-verdianas acreditam, ainda hoje, que a sua função é essencialmente reprodutora, onde a família, a cultura e a igreja, lhe incutem o ideal de "procriar, obedecer e sofrer" (idem, p.107).

Ao longo dos últimos anos, Cabo Verde tem procurado desenvolver políticas de apoio às mulheres, principalmente no domínio da saúde materna e saúde infantil, já que ser e nascer menina parece à partida, uma desvantagem. Foi em 1977, que entrou em funcionamento o primeiro Programa Materno Infantil e de Planeamento Familiar em Cabo Verde, muito devido ao elevado índice de mortalidade infantil e de famílias numerosas (Instituto Cabo-verdiana de Igualdade e Equidade do Género, 2014). Com a independência do povo cabo-verdiano, surgem diversos programas de políticas sociais, numa tentativa de combater a fome, reduzir a mortalidade infantil, promover o acesso à educação, à saúde e combater as questões de desigualdade de género (Lopes, 2002), porque a pobreza em Cabo Verde tem um cunho feminino, uma vez que ela atinge maioritariamente as mulheres. Neste sentido, e pela importância da temática, importa conhecermos de que forma os enfermeiros cabo-verdianos perspetivam a Mulher Caboverdiana, no que concerne às suas características, tal como, às suas necessidades em saúde.

\section{Metodologia}

O presente estudo insere-se numa metodologia qualitativa, onde participaram 38 enfermeiros cabo-verdianos, a frequentar formação de $2^{\circ}$ ciclo na área científica de enfermagem, tendo o estudo decorrido em Cabo Verde, durante o ano de 2020.

Com o objetivo de conhecer de que forma os enfermeiros cabo-verdianos perspetivam a Mulher Cabo-verdiana, no que concerne às suas características, tal como, às suas necessidades em saúde, definimos como questão de investigação que centraliza este trabalho: De que forma os enfermeiros cabo-verdianos perspetivam a Mulher Caboverdiana, no que concerne às suas características e às suas necessidades em saúde?

Os participantes no estudo foram selecionados intencionalmente em que como critérios de inclusão definimos: Ser enfermeiro; detentor da licenciatura em enfermagem; frequentar um curso de mestrado em enfermagem e aceitar participar voluntariamente na investigação.

No âmbito da colheita de dados recorreu-se à realização de um questionário, somente com duas questões abertas, nomeadamente: 1 . Pelas suas palavras, caracterize a Mulher Cabo-verdiana; 2. Pela sua experiência profissional, quais as necessidades em saúde da Mulher em Cabo Verde?

Para o tratamento destas questões procedeu-se à análise de conteúdo de Bardin (2011), segundo os pressupostos inerentes à metodologia qualitativa. Foram tidos em consideração todos os procedimentos formais e éticos, no que diz respeito à submissão do protocolo de investigação a uma comissão de ética (Parecer 676/06-2020), tal como 0 pedido de consentimento informado aos participantes do estudo.

\subsection{Análise de Conteúdo de Laurence Bardin}

A análise de conteúdo define-se "...como um conjunto de técnicas de análise das comunicações utilizando para tal procedimentos sistemáticos e objetivos de descrição do conteúdo das mensagens" (Bardin, 2011, p.40). A análise de conteúdo é uma técnica específica, que exige dedicação e tempo por parte dos investigadores, recorrendo à indução analítica para a definição de categorias e subcategorias de análise (Freitas, Cunha, \& Moscarola, 1997).

Tendo como referência a obra de Laurence Bardin, recorremos à análise de conteúdo como procedimento de análise de dados desta investigação, sendo que, segundo Flick (2009), a análise de conteúdo, além de realizar a interpretação após a colheita dos dados, desenvolve-se por meio de técnicas refinadas. 
No entanto, é preciso analisarmos criticamente os aspetos inerentes à 'numeração' dos achados, para que não possamos perder de vista o paradigma qualitativo em que a investigação se insere. Bardin (2006, p. 38) refere que a análise de conteúdo consiste num conjunto de técnicas de análise das comunicações, que utiliza procedimentos sistemáticos e objetivos de descrição do conteúdo das mensagens. Como afirma Chizzotti (2006, p. 98), "o objetivo da análise de conteúdo é compreender criticamente o sentido das narrativas, seu conteúdo manifesto ou latente, as significações explícitas ou ocultas", muito embora, vários investigadores têm criticado o recurso a indicadores quantitativos para salientar o sentido das narrativas, pressuposto este que foge ao que é esperado das metodologias qualitativas. Atendendo a que a análise de conteúdo constitui uma técnica de análise de dados que objetiva o encontro do significado da narrativa sobre determinado tema (Mozzato \& Grzybovski, 2011), há a necessidade da descodificação do que é dito. No entanto, na nossa opinião, este encontro de significado não se deve traduzir somente na translação de dados numéricos, já que as metodologias qualitativas têm, segundo Streubert e Carpenter (2002), características importantes, como a crença que existem múltiplas realidades; a abordagem visa em fim último à compreensão do fenómeno estudado; os participantes são centrais no processo investigativo; a pesquisa deve limitar a corrupção do contexto natural do fenómeno de interesse e uma compreensão do fenómeno, que se traduz de forma literária com recurso às narrativas dos participantes.

Bardin (2011) enuncia que o processo de análise de conteúdo envolve 3 fases ou etapas: a pré-análise, a exploração do material e por último, o tratamento dos resultados, a inferência e a interpretação, tendo sido estas etapas que seguimos no decurso desta investigação, salvaguardando sempre a importância dos achados e o seu significado para os participantes.

$\mathrm{Na}$ etapa da pré-análise procurámos organizar todo o material a ser analisado, pelo que, organizámos dois blocos de dados. O primeiro refere-se ao primeiro objetivo do estudo e à primeira questão que foi colocada aos nossos participantes: "Pelas suas palavras, caracterize a Mulher Cabo-verdiana". O segundo bloco de dados diz respeito ao segundo objetivo do estudo e à segunda questão que foi colocada: "Pela sua experiência profissional, quais as necessidades em saúde da Mulher em Cabo Verde?". Desta forma, procurámos tornar operacional os dados colhidos.

Após a sua organização em dois blocos centrais, desenvolvemos subsequentemente

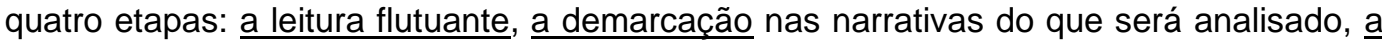
formulação das questões (entendemos que o questionamento é a atividade subjacente à análise de conteúdo) que advêm dos dados, e por último, a referenciação dos índices e elaboração de indicadores, que envolve a determinação de indicadores por meio de recortes de texto nos documentos de análise (Bardin, 2006), que sustentam a interpretação final.

Seguidamente entrámos na segunda fase, a chamada exploração do material, que consistiu na exploração do material com a definição de categorias (sistemas de codificação) e a identificação das unidades de registo (unidade de significação a codificar, segmento de conteúdo a considerar como unidade base, visando a categorização e a contagem frequencial) e das unidades de contexto (unidade de compreensão para codificar a unidade de registo que corresponde ao segmento da mensagem, a fim de compreender a significação exata da unidade de registo). Esta etapa é extremamente importante, porque possibilita o processo interpretativo. Se efetivamente a codificação, a classificação e a categorização são básicas nesta fase (Bardin, 2006), os investigadores, sob o paradigma indutivo, não devem perder-se tão-somente naquilo que a contagem frequencial Ihes revela, mas na descrição analítica dos achados encontrados, orientados pelos referenciais conceptuais e teóricos que os possam sustentar. A análise de conteúdo, enquanto técnica de investigação qualitativa, procura encontrar respostas centrada na experiência social, "tal como é criada e dá sentido à vida humana" (Streubert \& Carpenter, 2002, p. 2). 
Efetivamente o processo de codificação e categorização possibilitaram as interpretações e as inferências, e foi efetivamente durante este processo que os investigadores transformaram os dados brutos das diferentes respostas que tinham face aos dois blocos de dados, em dados significativos, recorrendo às técnicas de recorte, agregação e enumeração, permitindo "atingir uma representação do conteúdo, ou da sua expressão" (Bardin, 2006, p. 103).

Para Bardin (2006) a terceira etapa diz respeito ao tratamento dos resultados, inferência e interpretação. $O$ tratamento dos resultados obtidos, a inferência e a interpretação, compreendem operações a que os dados brutos são sujeitos, para assim se tornarem significativos e o investigador poder fazer inferências, recorrendo à intuição, à análise reflexiva e crítica. Gostaríamos aqui de salientar, que mais que as operações de contagem frequencial (que consideramos ser um meio para salientar a importância de determinados dados e não um meio de reflexão sobre esses mesmo dados, para o contexto significativo dos participantes na investigação), os investigadores centraram-se na condensação e no destaque das informações para análise, culminando nas interpretações.

Para Thompson (1995) e Denzin e Lincoln (2000) estas três etapas só fazem sentido se os investigadores forem munidos de ferramentas que Ihes permitam fazer uma análise contextual e histórica, recorrendo sistematicamente à intuição e à crítica.

Atendendo a esta reflexão realizada neste artigo, sobre a contagem frequencial das unidades de registo referente à segunda etapa do processo de análise de conteúdo de Bardin (2006) e o risco de se transformar esta metodologia numa análise mais numérica dos dados do que o seu próprio significado, Flick (2009, pp. 292-293) citando Mayring (1983), propõe-nos uma metodologia de análise de conteúdo assente em três fases: síntese da análise de conteúdo, por meio da omissão de enunciados; análise explicativa de conteúdo, com o esclarecimento de trechos difusos, ambíguos ou contraditórios; por fim, a análise estruturadora de conteúdo, por meio da estruturação no nível formal relativo ao conteúdo. Também Bardin (2006) reflete sobre estes aspetos, onde, se por um lado procurou através da sua metodologia o rigor da objetividade e da cientificidade, por outro, salvaguarda que não se deve perder nunca a riqueza da subjetividade, pois é isso que dá sentido à própria metodologia.

\section{Resultados e Discussão}

Como referido anteriormente participaram no estudo 38 enfermeiros cabo-verdianos, a frequentar formação de $2^{\circ}$ ciclo na área científica de enfermagem. Os participantes foram confrontados com duas questões abertas, que se dicotomizaram em dois blocos de dados. O primeiro bloco de dados centrou-se na perspetiva dos enfermeiros sobre a Mulher Caboverdiana, no que concerne às suas características e o segundo bloco de dados referente às necessidades em saúde destas mulheres.

Face ao primeiro bloco de dados, e atendendo às etapas explicitadas no segundo capítulo deste artigo, verificou-se que os enfermeiros atribuíram como características das mulheres cabo-verdianas o facto de serem mulheres trabalhadoras (1를 categoria), que vivenciam maioritariamente a sua vida no espaço doméstico ( $2^{\mathrm{a}}$ categoria), sendo muitas das vezes vitimas ( $3^{\mathrm{a}}$ categoria), com características humanas muito presentes (4 ${ }^{\mathrm{a}}$ categoria), onde a educação (do ponto de vista da literacia) é baixa (5 $5^{\underline{a}}$ categoria).

Pela análise detalhada de cada categoria constituída por diferentes unidades de registo, verifica-se que os enfermeiros atribuem às mulheres cabo-verdianas, mulheres muito trabalhadoras, embora confinadas ao espaço doméstico. Pela análise destas duas categorias na tabela 1 verificamos igualmente, que são atributos dados às mulheres caboverdianas serem corajosas e fortes, batalhadoras e guerreiras, considerando-as sobrecarregadas na dimensão do trabalho.

"Mulher cabo-verdiana é guerreira, apesar dos constrangimentos trabalha duramente para sustento dos filhos e demais membros da família" (E1). 
No espaço doméstico, estas mulheres são percecionadas como chefes de família, mulheres-mães, cuidadoras, educadoras e companheiras.

"Muitas vezes desempenham inúmeros papéis, a de ser mãe e pai ao mesmo tempo na educação dos filhos, devido ausência ou falta de assunção de responsabilidade dos homens, mulher dona de casa, trabalhadora, mas consegue sempre dar resposta" (E2).

Percecionadas como vítimas, terceira categoria, estas mulheres são consideradas como invisíveis para a sociedade, onde situações de violência de género são frequentes, levando a serem percecionadas pelos profissionais de saúde como mansas e humildes.

"Foram consideradas em muitas situações, meramente objeto de reprodução e a questão da educação era vista como um direito exclusivamente dos homens..." (E6).

Como seres humanos, quarta categoria, são consideradas como resilientes, criativas e humanas, onde prevalece, na quinta categoria, uma imagem de baixa literacia.

Tabela 1. Perceção dos profissionais sobre as características das mulheres cabo-verdianas.

\begin{tabular}{|c|c|c|c|}
\hline Categoria & Subcategoria & $\begin{array}{l}\text { Unidade de } \\
\text { significação }\end{array}$ & $\begin{array}{l}\mathrm{n} . \% / \text { contagem } \\
\text { frequencial }\end{array}$ \\
\hline \multirow{23}{*}{$\begin{array}{l}\text { Mulher } \\
\text { cabo- } \\
\text { verdiana }\end{array}$} & \multirow{6}{*}{ Trabalho } & Trabalhadora & 15 \\
\hline & & $\begin{array}{l}\text { Corajosa e } \\
\text { Forte }\end{array}$ & 14 \\
\hline & & Batalhadora & 13 \\
\hline & & Guerreira & 9 \\
\hline & & $\begin{array}{c}\text { Sobrecarregad } \\
\text { a }\end{array}$ & 5 \\
\hline & & $\begin{array}{c}\text { Total da } \\
\text { Categoria }\end{array}$ & 56 \\
\hline & \multirow{6}{*}{$\begin{array}{c}\text { Espaço } \\
\text { Doméstico }\end{array}$} & $\begin{array}{l}\text { Chefe de } \\
\text { Família }\end{array}$ & 18 \\
\hline & & Mulher-Mãe & 30 \\
\hline & & Cuidadora & 5 \\
\hline & & Educadora & 3 \\
\hline & & Companheira & 3 \\
\hline & & $\begin{array}{c}\text { Total da } \\
\text { Categoria } \\
\end{array}$ & 59 \\
\hline & \multirow{5}{*}{ Vítimas } & Invisíveis & 10 \\
\hline & & $\begin{array}{l}\text { Violência de } \\
\text { género }\end{array}$ & 5 \\
\hline & & Mansa & 3 \\
\hline & & Humilde & 3 \\
\hline & & $\begin{array}{c}\text { Total da } \\
\text { Categoria }\end{array}$ & 21 \\
\hline & \multirow{4}{*}{ Ser Humano } & Resiliente & 7 \\
\hline & & Criativa & 3 \\
\hline & & Humana & 3 \\
\hline & & $\begin{array}{c}\text { Total da } \\
\text { Categoria }\end{array}$ & 13 \\
\hline & \multirow[b]{2}{*}{ Educação } & Baixa Literacia & 5 \\
\hline & & $\begin{array}{c}\text { Total da } \\
\text { Categoria }\end{array}$ & 5 \\
\hline
\end{tabular}

No que concerne ao segundo bloco de dados, referente às necessidades em saúde destas mulheres, os enfermeiros consideram como fundamental o acesso a consultas de saúde da mulher de forma gratuita.

“...muitas vezes para além do dinheiro para ir à consulta, são condicionadas pela localização geográfica que tenham de deslocar até ao local da prestação dos serviços de saúde" (E1). 
A prevenção da violência baseada no género é outra das necessidades em saúde apontadas pelos profissionais, tal como a qualidade dos cuidados obstétricos, a despenalização do aborto e o aumento da literacia em saúde.

Os dados por nós apresentados fazem-nos refletir que os enfermeiros de Cabo Verde trazem com eles uma narrativa histórica da construção do Ser Mulher em Cabo Verde. O género e a raça, continuam a perpetuar a ideia da mulher submissa, dependente e pouco participativa na sociedade. Se hoje se assiste a uma valorização da mulher cabo-verdiana, ao aumento do número de mulheres a frequentar o ensino, tal como, a uma política de empoderamento das mulheres em Cabo Verde, ainda subsistem muitas mulheres vítimas de desigualdade e violência de género, e é esse olhar predominante sobre as mulheres cabo verdianas que os profissionais de saúde no geral, e os enfermeiros em particular nos remetem, o que vai ao encontro de Camacho (2010), Carvalho (2015) e Gonçalves (2017). Estes achados remetem para a necessidade de continuarmos a desenvolver projetos e programas de apoio à mulher cabo-verdiana, seja do ponto de vista da sua saúde, seja do ponto de vista económico-social.

\section{Conclusões}

Esta pesquisa permitiu-nos ir ao encontro da perspetiva dos enfermeiros cabo-verdianos face às características da mulher cabo-verdiana e das suas necessidades em saúde. Percebemos, pelos resultados, que as mulheres cabo-verdianas, ainda hoje, são caracterizadas como mulheres muito trabalhadoras, centradas ao espaço doméstico, muitas vezes vítimas de violência de género, e com baixa literacia.

No que concerne às necessidades em saúde, identifica-se que os enfermeiros consideram como necessário o acesso das mulheres cabo-verdianas a consultas gratuitas no âmbito da saúde da mulher e a melhores cuidados no domínio da saúde materna e obstétrica. Segundo Haraway (1995, p. 12), o mundo real e os problemas reais, do género ou da raça, não podem ser olhados com olhos cínicos de quem maquilha uma realidade socialmente construída por jogos de poderes, porque, "a doutrina ideológica do método científico e toda a verborragia filosófica a respeito da epistemologia tinham sido inventadas para distrair nossa atenção de chegar ao conhecimento do mundo efetivamente através da prática da ciência."

Através da metodologia da análise de conteúdo, procurámos não só desvelar as características e as necessidades em saúde de mulheres cabo-verdianas pelos olhos de quem cuida delas, como desvelar que questões como o género, a raça são muitas vezes conceitos e construções alvo de estigmatização política, social e económica, assistindose muitas vezes à simulação ou a uma co-construção sobre estas realidades, mais ou menos favoráveis aos meios onde se situam.

A utilização da metodologia qualitativa da análise de conteúdo neste estudo permitiu-nos, uma análise sistemática e aceder a uma grande quantidade de dados que é impossível aqui traduzir, sendo que, procurámos sempre salvaguardar que a redução a uma contagem frequencial não nos afastasse do significado particular de cada categoria e de cada unidade de registo. Mais que a sua expressão numérica, o que interessa aqui demarcar, é que os resultados do nosso estudo tornam evidente que estamos perante uma problemática de género, que persiste no tempo, a que os profissionais de saúde são chamados a dar resposta, pois por cada achado encontrado estará uma mulher.

Entendemos que o estudo apresentado apresenta algumas limitações, não só quanto ao numero de participantes, que é reduzido, por outro, o estudo utilizou como recurso um questionário, já que não era possível aos investigadores entrevistarem este numero de profissionais de saúde, atendendo ao tempo que dispunham para a realização da pesquisa. 


\section{Referências}

Bardin, L. (2006). Análise de conteúdo. Edições 70. Lisboa. Portugal

Bardin, L. (2011). Análise de conteúdo (L. de A. Rego \& A. Pinheiro, Trads.). Lisboa: Edições 70. (Obra original publicada em 1977)

Camacho, E. B. (2010). A Participação das Mulheres na Política em Cabo Verde: 1975-2006 (Bachelor's thesis). Disponivel em www.portaldoconhecimento.gov.cv

Carvalho, C. S. (2015). A Questão De Gênero Na Agenda Pública E Política De Cabo Verde África: Papel das ONG Feministas na Luta pelos Direitos das Mulheres. Outros Tempos Pesquisa em Foco-História, 12(19).

Chizzotti, A. (2006). Pesquisa em ciências humanas e sociais (8a ed.). São Paulo: Cortez.

Denzin, N. K., \& Lincoln, Y. S. (2000). Handbook of qualitative research (2nd ed.). Thousand Oaks: Sage publications.

Flick, U. (2009). Introdução à pesquisa qualitativa (3a ed., J. E. Costa, Trad.). São Paulo: Artmed. (Obra original publicada em 1995)

Freitas, H. M. R., Cunha, M. V. M., Jr., \& Moscarola, J. (1997). Aplicação de sistemas de software para auxílio na análise de conteúdo. Revista de Administração da USP, 32(3), 97-109.

Gomes, C. (2011). Mulher e Poder: O caso de Cabo Verde. IBNL, Praia. ICIEG 2008 Mulheres e Homens em Cabo Verde. Factos e Números.

Gonçalves, L. M. M. (2017). Participação da mulher na política em Cabo Verde. http://repositorio.unilab.edu.br/jspui/bitstream/123456789/786/1/2017_proj_lgoncalves.pdf

Haraway D. (1995). Saberes Localizados: a questão da ciência para o feminismo e o privilégio da perspectiva parcial. Cadernos pagu, (5), pp. 07-41.

Instituto Cabo-verdiana de Igualdade e Equidade do Género (2014). Relatório Cabo Verde Beijing +20. Républica de Cabo Verde.

Lopes, J. (2002). Cabo Verde: as causas da independência (e o estado de transição Democrática na África Lusófona). Spleen edições. Colecção Xis da Questão. Cidade da Praia.

Mozzato, A. \& Grzybovski, D. (2011). Análise de Conteúdo como Técnica de Análise de Dados Qualitativos no Campo da Administração: Potencial e Desafios. RAC, Curitiba, v. 15, n. 4, pp. 731-747, Jul./Ago. 2011.

Streubert, H. \& Carpenter, D. (2002). Investigação Qualitativa em Enfermagem. Lusociência, Edições técnicas e cientificas.

Thompson, J. B. (1995). Ideologia e cultura moderna: teoria social crítica na era dos meios de comunicação de massa (2a ed., Grupo de Estudos sobre Ideologia, Comunicação e Representações Sociais da Pós-Graduação do Instituto de Psicologia da PURCS, Trad.). Rio de Janeiro: Vozes. (Obra original publicada em 1990). 